\title{
Inadvertent hypothermia in hip and knee total joint arthroplasty ${ }^{\text {i }}$
}

\author{
M. Williams ${ }^{\mathrm{a}, *}$, Y. El-Houdiri ${ }^{\mathrm{b}}$ \\ a Department of Trauma and Orthopaedic Surgery, Torbay Hospital, Torquay, Devon, TQ2 7AA, United kingdom \\ ${ }^{\mathrm{b}}$ Department of Trauma and Orthopaedic Surgery, Torbay Hospital, Torquay, Devon, TQ2 7AA, United kingdom
}

\section{A R T I C L E I N F O}

\section{Keywords:}

Total joint arthroplasty

Total knee arthroplasty

Total knee replacement

Total hip arthroplasty

Total hip replacement

Revision arthroplasty

Hypothermia

\begin{abstract}
A B S T R A C T
Background: This clinical study aims to establish rates of inadvertent hypothermia (IH) in both primary and revision total hip/knee arthroplasty (THA/TKA and rTHA/rTHA). We postulate differences exist between demographic, surgical and anesthetic variables and outcomes for IH and normothermic patients. Methods: We conducted a single centre, retrospective study of 2431 total joint arthroplasty (TJA) patients having undergone THA $(n=1096)$, TKA $(n=1083)$, rTHA $(n=165)$ and rTKA $(n=87)$ from March 2013 to December 2016. Outcomes include length of stay (LOS), 31-day complication rates for thrombotic events and infection and 31-day readmission rates (RR).

Results: Overall rates of IH were 11.7\%; with cohort analysis demonstrating rates of $13.2 \%, 11.2 \%, 8.3 \%$ and $3.9 \%$ in THA, TKA, rTHA and rTKA respectively. Patients with body mass index (BMI) $<29 \mathrm{~kg} / \mathrm{m}^{2}$ and $\mathrm{un}-$ dergoing THA were at risk of IH. For all TJA, no difference was observed in 31-day complications (1.6\% vs. $2.8 \%, p=0.19), 31$-day RR $(3.3 \%$ vs. $4.5 \%, p=0.50)$ or $\operatorname{LOS}(4.6 \pm 2.9$ vs. $5.1 \pm 4.5, p=0.11)$. IH was associated with higher RR for haematoma in TKA ( $2.9 \%$ vs. $0.4 \%, \mathrm{p}=0.021)$ and higher deep infection rates in rTHA (20\% vs $0 \%, \mathrm{p}=0.006)$.

Conclusion: Our study demonstrates a $3.9 \%$ to $13.2 \%$ rate of IH in TJA, with lower BMI, THA and primary cases as risk factors. We recommend protective steps are taken to maintain patient normothermia in these groups.
\end{abstract}

\section{Introduction}

Total joint arthroplasty (TJA) patients are at risk of inadvertent hypothermia $(\mathrm{IH})$ during surgery due to uncovered and exposed tissues skin, anaesthesia eliminating normal protective thermo-regulatory reflexes and using fluid intravenously and for wound irrigation. IH results in unpleasant post-operative shivering on return of the patient's homeostatic control. ${ }^{1}$ Further deleterious sequelae of peri-operative IH include an increased blood transfusion requirement, infection, myocardial infarction, ventilation and mortality. ${ }^{2}$ Furthermore, IH results in longer ITU stay and longer length of stay (LOS) with is associated cost implications. $^{2}$

Studies in multiple surgical specialty cohorts have found pre-operative warming, active warming, high baseline core temperature, and high ambient temperature is protective against $\mathrm{IH}^{3}$ Finding from nonorthopaedics cohorts postulate that the resultant vasoconstriction from intra-operative IH slows healing and increases surgical wound infection rates. Indeed, pre-operative warming is associated with lower wound infection rates in general surgical patients. ${ }^{4}$ Extrapolating these findings for orthopaedic surgery engenders a desire to maintain patient normothermia. Indeed, the National Institute for Health and Care Excellence (NICE) Guidelines (CG65) offer recommendations for maintaining intra-operative normothermia, including the use of warming devices. The beneficial effects of warming are mediated through increased blood flow and oxygen tension at tissue level. ${ }^{5}$ Despite this, studies report IH rates of $26.3-43.9 \%$ for THA and $28.0-32.6 \%$ for TKA. ${ }^{6,7}$ There remains a paucity of data delineating risk factors associated with IH in elective TJA. We investigate the IH rates in our institute, hypothesizing lower IH rates for both primary total hip/knee arthroplasty (THA/TKA) compared with revision total hip/knee arthroplasty (rTHA/rTKA). We postulate differences exist between demographic, surgical and anesthetic variables and outcomes for $\mathrm{IH}$ and normothermic patients.

\section{Methods}

We conducted a retrospective study a TJA patients $(n=2431)$ with differentiation into operation type (THA $n=670$, TKA $n=607$, rTHA $\mathrm{n}=99$ and rTKA $\mathrm{n}=54$ ) from March 2013 to December 2016. We compare patients who were hypothermic on leaving theatre with those

\footnotetext{
Clinical study conducted at: Department of Trauma and Orthopaedic Surgery, Torbay Hospital, Torquay, Devon, TQ2 7AA, United kingdom.

* Corresponding author at: Department of Trauma and Orthopaedic Surgery, Torbay Hospital, Torquay, Devon, TQ2 7AA, United kingdom.

E-mail addresses: m.williams13@nhs.net (M. Williams), yel-houdiri@nhs.net (Y. El-Houdiri).
} 
Table 1

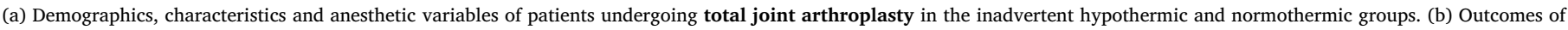
patients undergoing total joint arthroplasty with two cohorts: inadvertent hypothermic and normothermic groups.

\begin{tabular}{|c|c|c|c|c|}
\hline & All & Hypothermic & Normothermic & $P$ value \\
\hline Number of joints & 2431 & $240(11.7)$ & $1815(88.3)$ & \\
\hline Mean Age \pm SD (range) & 72.3 yrs $\pm 10.4(17.8-96.6)$ & $72.0 \pm 10.0(37.2-94.9)$ & $71.3 \pm 10.3(17.8-93.5)$ & 0.32 \\
\hline \multicolumn{5}{|l|}{ Gender (\%) } \\
\hline Male & 1001 (41.7) & $144(61.3)$ & $751(42.0)$ & 0.35 \\
\hline Female & $1397(58.3)$ & $91(38.7)$ & $1039(58.0)$ & \\
\hline \multicolumn{5}{|l|}{ Laterality (\%) } \\
\hline Left & 1138 (46.9) & $126(52.5)$ & $964(53.3)$ & 0.96 \\
\hline Right & $1280(52.8)$ & $113(47.1)$ & $840(46.4)$ & \\
\hline Bilateral & $8(0.3)$ & $1(0.4)$ & $6(0.3)$ & \\
\hline \multicolumn{5}{|l|}{ Operation (\%) } \\
\hline TKA & $1083(44.5)$ & $104(43.4)$ & $821(45.2)$ & 0.045 \\
\hline THA & $1096(45.1)$ & $123(51.3)$ & $810(44.6)$ & \\
\hline Revision TKA & $87(3.6)$ & $3(1.3)$ & $74(4.1)$ & \\
\hline Revision THA & $165(6.8)$ & $10(4.2)$ & $110(6.1)$ & \\
\hline \multicolumn{5}{|l|}{ Indication (\%) } \\
\hline Elective & $2356(97.0)$ & $236(98.3)$ & $1756(96.8)$ & 0.19 \\
\hline Trauma & $73(3.0)$ & $4(1.7)$ & $58(3.2)$ & \\
\hline Mean ASA grade \pm SD & $2.29 \pm 0.58$ & $2.20 \pm 0.56$ & $2.23 \pm 0.55$ & 0.50 \\
\hline Mean BMI \pm SD & $30.4 \pm 5.7$ & $29.5 \pm 5.3$ & $30.5 \pm 5.7$ & 0.019 \\
\hline \multicolumn{5}{|l|}{ BMI (\%) } \\
\hline$\geq 30 \mathrm{~kg} / \mathrm{m}^{2}$ & $847(51.7)$ & $88(44.7)$ & $759(52.6)$ & 0.036 \\
\hline$<29 \mathrm{~kg} / \mathrm{m}^{2}$ & $792(48.3)$ & $109(55.3)$ & $683(47.4)$ & \\
\hline \multicolumn{5}{|l|}{ Ethnicity (\%) } \\
\hline White (British/Irish) & $2355(98.8)$ & $233(97.9)$ & $1750(98.8)$ & 0.33 \\
\hline White \& Black Caribbean & $1[0]$ & 0 & $1(0.1)$ & \\
\hline Other White Background & $19(0.8)$ & $3(1.3)$ & $14(0.8)$ & \\
\hline White \& Asian & $2(0.1)$ & 0 & $2(0.2)$ & \\
\hline Other Asian Background & $4(0.2)$ & $2(0.8)$ & $2(0.1)$ & \\
\hline Indian & $2(0.1)$ & 0 & $2(0.1)$ & \\
\hline Black & $1[0]$ & 0 & $1(0.1)$ & \\
\hline \multicolumn{5}{|l|}{ Anaesthesia type (\%) } \\
\hline Regional & $1365(56.1)$ & 139 (57.9) & $995(54.8)$ & 0.41 \\
\hline General & $903(37.1)$ & $90(37.5)$ & $691(38.1)$ & \\
\hline LA + Sedation & $163(6.7)$ & $11(4.7)$ & $129(7.1)$ & \\
\hline Operative time $\pm \mathrm{SD}$ & $106.2 \pm 43.4$ & $99.9 \pm 28.5$ & $104.9 \pm 41.6$ & 0.068 \\
\hline Time in theatre \pm SD & $139.0 \pm 49.1$ & $130.8 \pm 33.0$ & $137.4 \pm 47.1$ & 0.036 \\
\hline \multicolumn{5}{|l|}{ Warming Device (\%) Blanket } \\
\hline Yes & $60(8.7)$ & $6(12.2)$ & $44(8.8)$ & 0.42 \\
\hline No & $629(91.3)$ & $43(87.8)$ & $455(91.2)$ & \\
\hline \multicolumn{5}{|l|}{ Fluid Warmer } \\
\hline Yes & $397(57.6)$ & $30(61.2)$ & $284(56.9)$ & 0.56 \\
\hline No & $292(42.4)$ & $19(38.8)$ & $215(43.1)$ & \\
\hline \multicolumn{5}{|l|}{ Forced Air Blanket } \\
\hline Yes & $669(97.1)$ & 49 [100] & $488(97.8)$ & 0.61 \\
\hline No & $20(2.9)$ & 0 & $11(2.2)$ & \\
\hline \multicolumn{5}{|l|}{ Heated Mattress } \\
\hline Yes & $6(0.9)$ & 0 & $6(1.2)$ & 1.0 \\
\hline No & $683(99.1)$ & 49 [100] & $493(98.8)$ & \\
\hline
\end{tabular}

\begin{tabular}{|c|c|c|c|c|}
\hline Variable & All & Hypothermic $(n=240)$ & Normothermic $(\mathrm{n}=1815)$ & $P$ value \\
\hline Length of Stay (SD) & $5.4 \pm(4.9)$ & $4.6 \pm 2.9$ & $5.1 \pm 4.5$ & 0.11 \\
\hline 31-day Complications (\%) & & $3(1.6)$ & $52(2.8)$ & 0.19 \\
\hline $\mathrm{PE}$ & $12(0.5)$ & 0 & $12(0.7)$ & 0.38 \\
\hline DVT & $4(0.2)$ & 0 & $4(0.2)$ & 1.0 \\
\hline SSSI & $9(0.4)$ & $1(0.4)$ & $8(0.4)$ & 1.0 \\
\hline DSSI & $13(0.5)$ & $1(0.4)$ & $12(0.7)$ & 1.0 \\
\hline CVE & $14(0.6)$ & $1(0.4)$ & $13(0.7)$ & 1.0 \\
\hline MI & $3(0.1)$ & 0 & $3(0.2)$ & 1.0 \\
\hline \multicolumn{5}{|l|}{ 31-day Re-admissions (\%) } \\
\hline All & $90(3.7)$ & $8(3.3)$ & $82(4.5)$ & 0.50 \\
\hline $\mathrm{PE}$ & $10(0.4)$ & 0 & $10(0.6)$ & 0.62 \\
\hline DVT & $3(0.1)$ & 0 & $3(0.2)$ & 1.0 \\
\hline SSSI & $8(0.3)$ & 0 & $8(0.4)$ & 0.61 \\
\hline DSSI & $13(0.5)$ & $1(0.4)$ & $12(0.7)$ & 1.0 \\
\hline Wound problem & $6(0.2)$ & $2(0.8)$ & $4(0.2)$ & 0.15 \\
\hline Pain & $15(0.6)$ & 0 & $15(0.8)$ & 0.24 \\
\hline
\end{tabular}


Table 1 (continued)

\begin{tabular}{|c|c|c|c|c|}
\hline Variable & All & Hypothermic $(\mathrm{n}=240)$ & Normothermic $(\mathrm{n}=1815)$ & $P$ value \\
\hline LRTI & $3(0.1)$ & 0 & $3(0.2)$ & 1.0 \\
\hline Haematoma & $12(0.5)$ & $3(1.2)$ & $9(0.5)$ & 0.16 \\
\hline Dislocation & $12(0.5)$ & $2(0.8)$ & $10(0.6)$ & 0.64 \\
\hline CVE & $6(0.2)$ & 0 & $6(0.3)$ & 1.0 \\
\hline Anaemia & $2(0.1)$ & 0 & $2(0.1)$ & 1.0 \\
\hline
\end{tabular}

that were not. We compare demographic details to include: age, implant type, gender, laterality, American Society of Anasthesiology grade (ASA), Body Mass Index (BMI) and ethnicity. Anasthetic and surgical variables analysed include: anesthetic type, operative type, operative time, theatre time, presence of warming device (blanket, forced air blanket, fluid warmer, heated mattress).

All patients were had baseline core temperature $>36^{\circ}$ on entering theatre. The primary outcome was $\mathrm{IH}$, defined as core temperature $<36{ }^{\circ} \mathrm{C}$ when measured after closure. Tympanic membrane temperature was used as it is easily obtained, reflect current practice and has been validated to reflect core temperature. Secondary outcomes measured include LOS, 31-day complication rates for thrombotic events and infection, and 31-day re-admission rates.

\subsection{Statistical analysis}

Nominal and ordinal data is presented as case numbers and proportions with comparison used chi-square analysis. Continuous data is presented as mean and standard deviation with comparison using $t$-test. Statistical significance is set at the $95 \%$ confidence interval. SPSS (IBM Corp. in Armonk, NY) was used for analysis.

\section{Results}

Overall rates of $\mathrm{IH}$ were $11.7 \%(\mathrm{n}=240)$, with the highest rates observed in primary THA (13.2\%) and TKA (11.2\%). Examining all cohorts, comparable patient demographics were seen in $\mathrm{IH}$ and normothermic groups with a mean age of $72.0 \pm 10.0$ vs. $71.3 \pm 10.3$ $(\mathrm{p}=0.32)$, mean ASA grade $2.20 \pm 0.56$ vs. $2.23 \pm 0.55(\mathrm{p}=0.50)$ with a majority white British or Irish ethnicity (98.8\%). Additionally, comparable laterality, trauma to elective ratio, male to female ratio and aesthetic type were noted (see Table 1a). Overall regional anaesthesia techniques were used most frequently accounting for $56.1 \%$ of cases, followed by general anaesthesia in $37.1 \%$ of cases.

Considering all TJA patients a significantly lower mean BMI of $29.5 \pm 5.3 \mathrm{~kg} / \mathrm{m}^{2}$ vs. $30.5 \pm 5.7 \mathrm{~kg} / \mathrm{m}^{2}(\mathrm{p}=0.019)$ and higher proportion of THA $51.3 \%$ vs. $44.6 \%(\mathrm{p}=0.045)$ were in the IH vs. normothermic groups. Obese patients, defined as BMIs $\geq 30 \mathrm{~kg} / \mathrm{m}^{2}$, were significantly less likely to experience IH than those with BMI $<29 \mathrm{~kg}$ / $\mathrm{m}^{2}(\mathrm{p}=0.036)$. Shorter operative times were observed, although not statistically significant, in the IH vs normothermic group, $99.9 \pm 28.5 \mathrm{mins}$ vs. $104.9 \pm 41.6 \mathrm{mins}(\mathrm{p}=0.068)$. No difference was observed between groups for the presence or absence of individual warming devices. Similarly, no difference between groups was seen for 31-day complications, $1.6 \%(\mathrm{n}=3)$ vs. $2.8 \%(\mathrm{n}=52)(\mathrm{p}=0.19)$, 31day RR, $3.3 \%(\mathrm{n}=8)$ vs. $4.5 \%(\mathrm{n}=82),(\mathrm{p}=0.32)$ or LOS, $4.6 \pm 2.9$ vs. $5.1 \pm 4.5(\mathrm{p}=0.11)$, see Table $1 \mathrm{~b}$.

Demographics for THA were comparable between groups with overall $92.6 \%(n=1015)$ of THA patients having cemented procedures (see Table 2a). Comparing the primary THA IH vs. normothermic groups, a lower BMI was seen, $28.3 \pm 5.1 \mathrm{~kg} / \mathrm{m}^{2}$ vs. $29.2 \pm 5.5 \mathrm{~kg} / \mathrm{m}^{2}$ $(\mathrm{p}=0.15)$. The proportion of obese THA patients in the IH vs. normothermia was $35.4 \%(n=34)$ vs. $44.0 \%(n=265)(p=0.11)$. No statistically significant differences were seen for $\operatorname{LOS}(p=0.30), 31$-day complications $(\mathrm{p}=0.38)$ and 31-day re-admission $(\mathrm{p}=0.76)$, see Table $2 \mathbf{b}$.
A variable nearing significance for TKA was BMI, where lower BMIs of $30.6 \pm 5.2 \mathrm{~kg} / \mathrm{m}^{2}$ vs. $31.6 \pm 5.6 \mathrm{~kg} / \mathrm{m}^{2}$ were noted in the $\mathrm{IH}$ vs. normothermic $(\mathrm{p}=0.11)$, see Table 3 a. $53.2 \%(\mathrm{n}=50)$ vs. $60.1 \%$ $(\mathrm{n}=432)$ of TKA with obesity had IH vs. normothermia $(\mathrm{p}=0.20)$. A tendency for higher rates of wound problems $1.9 \%(\mathrm{n}=2)$ vs $0.5 \%$ $(\mathrm{n}=4)(\mathrm{p}=0.14)$ and haematoma $2.9 \%(\mathrm{n}=3)$ vs. $0.4 \%(\mathrm{n}=3)$ $(\mathrm{p}=0.021$ ) was seen in the IH group (see Table $3 \mathrm{~b}$ ).

Rates of IH were $8.3 \%(n=10)$ for rTHA and $3.9 \%(n=3)$ for rTKA. For rTHA and rTKA, univariate analysis did not identify significant differences between groups for demographic, anaesthetic or surgical variables (see tables $4 \mathrm{a}$ and $5 \mathrm{a}$ ). BMI was comparable for rTHA groups $29.0 \pm 5.0$ vs. $29.3 \pm 5.1(\mathrm{p}=0.89)$ and rTKA groups, $36.7 \pm 8.0$ vs $31.9 \pm 6.6(\mathrm{p}=0.47)$. The rTHA IH group tended to have shorter operative times than the normothermic group $154.6 \pm 42.1$ vs. $181.1 \pm 58.5(\mathrm{p}=0.16)$. No differences in outcomes were seen for rTKA (see Table 4b). For rTHA, IH was associated with higher infection complications with deep infection rates of $20 \%$, $\mathrm{n}=2$ vs $0 \%(\mathrm{p}=0.006)$.

\section{Discussion}

NICE guidelines (CG65) outline strategies to avoid IH; maintaining patient normothermia intra-operatively and awareness by theatre teams is essential. We report higher rates of IH for primary THA than TKA, as demonstrated in others studies. ${ }^{7,6}$ Our data highlights that IH group had a statistically significantly lower BMI; concordant with evidence that lower BMI is a risk for $\mathrm{IH}$, which has been demonstrated during both regional and general anesthesia. That is, increase insulation by excessive fat in obese patients is protective against $\mathrm{IH}^{8}$ Employing additional strategies demonstrated to be protective, such as pre-operative warming and active warming in lower BMI patients may be warranted. ${ }^{3}$

Studies have demonstrated that general anaesthesia (GA) produces a dose dependent decrease in core body temperature by affecting the body's thermoregulatory systems, such as arteriovenous shunt vasoconstriction and shivering. ${ }^{9}$ However, in our study the proportion of patients receiving GA was not different in the IH vs. normothermic groups. Whilst Firsch et al., who found GA and female gender to be a risk factor for IH we did not.

We demonstrate $\mathrm{IH}$ to be associated with higher re-admissions for haematoma in TKA and infective complications in rTHA only. A study of 90 day VTE rates following a national change of venous thromboprophylaxis guidance established rate to range from $1.69-1.84 \%$ for THA and 1.99-2.04\% for TKA. National reported averages for SSI following THA and TKA is $0.5 \%$ for both ${ }^{10,11}$ Given these low incidences, collective data, such as joint registry data, would likely be required to demonstrate statistically significant differences in the absolute risk of VTE and infection for any given variable. That is, the null hypothesis that IH is associated with no difference in post-operative complications in elective orthopaedic patients requires further examination.

The United Kingdom National Joint Registry reported in 2015 for THA revision an average age of $70.12+/-11.69$ years with $57 \%$ with mild disease not incapacitating (P2) and 33\% incapacitating systemic disease (P3). In contrast, proportionally primary THA patients had better physical status with $69 \%$ classed as P2 s and $17 \%$ as P3 and an average age of 68.65 years $+/-11.32 .{ }^{12}$ Similar demographic differences are seen for primary compared with revision TKA; patients 
Table 2

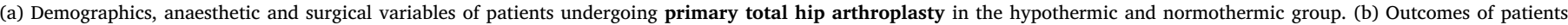
undergoing primary total hip arthroplasty with two cohorts: inadvertent hypothermic and normothermic groups.

\begin{tabular}{|c|c|c|c|c|}
\hline & All & Hypothermic & Normothermic & $P$ value \\
\hline Number of joints & 1096 & $123(13.2)$ & $810(86.8)$ & \\
\hline Mean Age \pm SD (range) & $72.7 \pm 11.1(17.8-95.5)$ & $72.6 \pm 10.8(45.7-94.9)$ & $71.5 \pm 11.2(17.8-93.5)$ & 0.32 \\
\hline \multicolumn{5}{|l|}{ Gender (\%) } \\
\hline Male & $427(39.3)$ & $43(35.5)$ & $307(38.2)$ & 0.57 \\
\hline Female & $659(60.7)$ & $78(64.5)$ & $496(61.8)$ & \\
\hline \multicolumn{5}{|l|}{ Laterality } \\
\hline Left & $587(53.7)$ & 70 (56.9) & $432(53.5)$ & 0.43 \\
\hline Right & $504(46.1)$ & $52(42.3)$ & $374(46.3)$ & \\
\hline Bilateral & $3(0.3)$ & $1(0.8)$ & $2(0.2)$ & \\
\hline \multicolumn{5}{|l|}{ Type } \\
\hline Elective & 1039 (94.8) & $119(96.7)$ & $760(93.8)$ & 0.20 \\
\hline Trauma & $57(5.2)$ & $4(3.3)$ & $50(6.2)$ & \\
\hline \multicolumn{5}{|l|}{ Type } \\
\hline Uncemented & $81(7.4)$ & $10(8.1)$ & 64 (7.9) & 0.93 \\
\hline Cemented & $1015(92.6)$ & $113(91.9)$ & $746(92.1)$ & \\
\hline Mean ASA grade & $2.29 \pm 0.6$ & $2.20 \pm 0.60$ & $2.22 \pm 0.57$ & 0.77 \\
\hline Mean BMI \pm SD & $29.1 \pm 5.5$ & $28.3 \pm 5.1$ & $29.2 \pm 5.5$ & 0.15 \\
\hline \multicolumn{5}{|l|}{ Anaesthesia type } \\
\hline Regional & $664(60.6)$ & $77(62.6)$ & $475(58.6)$ & 0.73 \\
\hline General & $359(32.8)$ & $40(32.5)$ & $281(34.7)$ & \\
\hline Local + Sedation & $73(6.6)$ & $6(4.8)$ & $54(6.7)$ & \\
\hline Operative time $\pm \mathrm{SD}$ & $106.2 \pm 28.3$ & $103.9 \pm 22.7$ & $105.6 \pm 27.9$ & 0.51 \\
\hline Time in theatre \pm SD & $139.7 \pm 33.4$ & $135.8 \pm 26.9$ & $138.6 \pm 32.8$ & 0.36 \\
\hline Warming device & & & & \\
\hline \multicolumn{5}{|l|}{ Blanket } \\
\hline Yes & $20(7.3)$ & $2(11.1)$ & $13(6.5)$ & 0.36 \\
\hline No & $255(92.7)$ & 16 (88.9) & $187(93.5)$ & \\
\hline \multicolumn{5}{|l|}{ Fluid-Warmer } \\
\hline Yes & $175(63.6)$ & $14(77.8)$ & $125(62.5)$ & 0.30 \\
\hline No & $100(36.4)$ & $4(22.2)$ & $14(77.8)$ & \\
\hline \multicolumn{5}{|l|}{ Forced-Air-Blanket } \\
\hline Yes & $266(96.7)$ & 18 [100] & $195(97.5)$ & 0.50 \\
\hline No & $9(3.3)$ & 0 & $5(2.5)$ & \\
\hline \multicolumn{5}{|l|}{ Heated-Mattress } \\
\hline Yes & $3(1.1)$ & 0 & $3(1.5)$ & 1.0 \\
\hline No & $272(98.9)$ & 18 [100] & $197(98.5)$ & \\
\hline
\end{tabular}

\begin{tabular}{|c|c|c|c|c|}
\hline & All $(n=1096)$ & Hypothermic $(\mathrm{n}=123)$ & Normothermic $(\mathrm{n}=810)$ & $P$ value \\
\hline Length of Stay (SD) & $5.2 \pm 3.2$ & $4.6 \pm 2.7$ & $4.9 \pm 3.0$ & 0.30 \\
\hline \multicolumn{5}{|c|}{ 31-day Complication Rate } \\
\hline All & & 0 & $12(1.5)$ & 0.38 \\
\hline $\mathrm{PE}$ & $3(0.3)$ & 0 & $3(0.4)$ & 1.0 \\
\hline DVT & $1(0.1)$ & 0 & $1(0.1)$ & 1.0 \\
\hline SSSI & $2(0.2)$ & 0 & $2(0.2)$ & 1.0 \\
\hline DSSI & $1(0.1)$ & 0 & $1(0.1)$ & 1.0 \\
\hline CVE & $2(0.2)$ & 0 & $2(0.2)$ & 1.0 \\
\hline MI & $3(0.3)$ & 0 & $3(0.4)$ & 1.0 \\
\hline \multicolumn{5}{|c|}{ 31-day Readmission Rate } \\
\hline All & $24(2.2)$ & $2(1.6)$ & $22(2.7)$ & 0.76 \\
\hline PE & $3(0.3)$ & 0 & $1(0.1)$ & 1.0 \\
\hline DVT & $1(0.1)$ & 0 & $1(0.1)$ & 1.0 \\
\hline SSSI & $2(0.2)$ & 0 & $2(0.2)$ & 1.0 \\
\hline DSSI & $1(0.1)$ & 0 & $1(0.1)$ & 1.0 \\
\hline Pain & $6(0.5)$ & 0 & $6(0.7)$ & 1.0 \\
\hline LRTI & $1(0.1)$ & 0 & $1(0.1)$ & 1.0 \\
\hline Haematoma & $3(0.3)$ & 0 & $3(0.4)$ & 1.0 \\
\hline Dislocation & $7(0.6)$ & $2(1.6)$ & $5(0.6)$ & 0.23 \\
\hline
\end{tabular}

undergoing revision are older and more co-morbid. ${ }^{12}$ These patient factors in combination with longer operative times and larger incisions used for revision cases, theoretically increase the risk of IH. However, we report lower rates of IH for revision TJA contrary to our hypothesis. We postulate that despite the larger magnitude of revision cases, lower $\mathrm{IH}$ rates occurred due to altered behaviors and increased protective steps taken to maintain patient normothermia.

A limitation to our study was the incomplete data for warming devices, resulting in fewer cases for analysis. We were unable to demonstrate a higher rate of $\mathrm{IH}$ given the presence or absence for any warming modality. Studies have suggested forced air warming was more effective than all other methods studies for maintaining 
Table 3

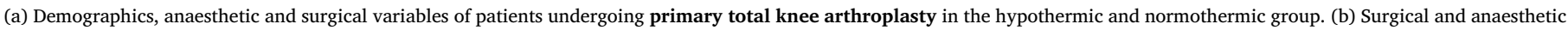
variables of patients with PRIMARY total KNEE arthroplasty in the hypothermic and normothermic group.

\begin{tabular}{|c|c|c|c|c|}
\hline & All & Hypothermic & Normothermic & $P$ value \\
\hline Number of joints & 1083 & $104(11.2)$ & $821(88.8)$ & \\
\hline Mean Age \pm SD (range) & $72.02 \mathrm{yr} \pm 9.09(33.6-96.6)$ & $70.9 \mathrm{yr} \pm 9.1(37.2-89.6)$ & $71.4 \mathrm{yr} \pm 8.8(33.6-91.8)$ & 0.65 \\
\hline \multicolumn{5}{|l|}{ Gender (\%) } \\
\hline Male & $455(42.8)$ & $43(42.6)$ & $353(43.9)$ & 0.80 \\
\hline Female & $607(57.2)$ & $58(57.4)$ & $451(56.1)$ & \\
\hline \multicolumn{5}{|l|}{ Laterality } \\
\hline Left & $572(52.9)$ & $50(48.1)$ & $447(54.6)$ & 0.36 \\
\hline Right & $505(46.7)$ & 54 (51.9) & $369(45.1)$ & \\
\hline Bilateral & $4(0.4)$ & 0 & $3(0.4)$ & \\
\hline \multicolumn{5}{|l|}{ Indication } \\
\hline Elective & 1081 (99.9) & $104[100]$ & $820[100]$ & \\
\hline Trauma & $1(0.1)$ & 0 & 0 & \\
\hline Mean ASA grade & $2.27 \pm 0.54$ & $2.17 \pm 2.69$ & $2.22 \pm 0.51$ & 0.45 \\
\hline Mean BMI & $31.4 \pm 5.7$ & $30.6 \pm 5.2$ & $31.6 \pm 5.6$ & 0.11 \\
\hline \multicolumn{5}{|l|}{ Anaesthesia type } \\
\hline Regional & $628(58.0)$ & $60(57.7)$ & $469(57.1)$ & 0.28 \\
\hline General & $373(34.4)$ & $40(38.5)$ & $282(34.3)$ & \\
\hline LA + Sedation & $82[75]$ & $4(3.9)$ & $70(8.5)$ & \\
\hline Operative time \pm SD & $88.3 \pm 26.8$ & $88.2 \pm 23.1$ & $87.6 \pm 27.4$ & 0.84 \\
\hline Time in theatre \pm SD & $118.5 \pm 30.9$ & $117.3 \pm 27.4$ & $117.7 \pm 31.3$ & 0.90 \\
\hline Warming device & & & & \\
\hline \multicolumn{5}{|l|}{ Blanket } \\
\hline Yes & $32(10.5)$ & $1(3.8)$ & $26(11.8)$ & 0.33 \\
\hline No & $273(89.5)$ & $25(96.2)$ & $195(88.2)$ & \\
\hline \multicolumn{5}{|l|}{ Fluid-Warmer } \\
\hline Yes & $162(53.1)$ & $11(42.3)$ & $119(53.8)$ & 0.30 \\
\hline No & $143(46.9)$ & $15(57.7)$ & $102(46.2)$ & \\
\hline \multicolumn{5}{|l|}{ Forced-Air-Blanket } \\
\hline Yes & $296(97.0)$ & $26[100]$ & $216(97.7)$ & 0.44 \\
\hline No & $9(3.0)$ & 0 & $5(2.3)$ & \\
\hline \multicolumn{5}{|l|}{ Heated-Mattress } \\
\hline Yes & $2(0.7)$ & 0 & $2(0.9)$ & 1.0 \\
\hline No & $303(99.3)$ & $26[100]$ & $219(99.1)$ & \\
\hline Variable & All & Hypothermic $(\mathrm{n}=104)$ & Normothermic $(\mathrm{n}=821)$ & $P$ value \\
\hline Length of Stay & $4.8 \pm 3.2$ & $4.2 \pm 2.7$ & $4.6 \pm 3.0$ & 0.29 \\
\hline \multicolumn{5}{|l|}{ 31-day Complication } \\
\hline All & & $2(0.2)$ & $33(4.0)$ & 0.42 \\
\hline $\mathrm{PE}$ & $8(0.7)$ & 0 & $8(1.0)$ & 0.60 \\
\hline DVT & $3(0.3)$ & 0 & $3(0.4)$ & 1.0 \\
\hline SSSI & $6(0.6)$ & $1(0.1)$ & $5(0.6)$ & 0.51 \\
\hline DSSI & $8(0.7)$ & $1(0.1)$ & $7(0.9)$ & 1.0 \\
\hline CVE & $10(0.9)$ & 0 & $10(1.2)$ & 0.61 \\
\hline \multicolumn{5}{|l|}{ 31-day Re-admission Rate } \\
\hline All & $41(3.8)$ & $6(5.8)$ & $35(5.0)$ & 0.45 \\
\hline $\mathrm{PE}$ & $6(0.6)$ & 0 & $6(0.7)$ & 1.0 \\
\hline DVT & $2(0.2)$ & 0 & $2(0.2)$ & 1.0 \\
\hline SSSI & $5(0.5)$ & 0 & $5(0.6)$ & 1.0 \\
\hline DSSI & $8(0.7)$ & $1(1.0)$ & $7(0.9)$ & 1.0 \\
\hline Wound problem & $6(0.6)$ & $2(1.9)$ & $4(0.5)$ & 0.14 \\
\hline Pain & $8(0.7)$ & 0 & $8(1.0)$ & 0.61 \\
\hline LRTI & $2(0.2)$ & 0 & $2(0.2)$ & 1.0 \\
\hline Haematoma & $6(0.6)$ & $3(2.9)$ & $3(0.4)$ & 0.021 \\
\hline CVE & $6(0.6)$ & 0 & $6(0.7)$ & 1.0 \\
\hline Anaemia & $1(0.1)$ & 0 & $1(0.1)$ & 1.0 \\
\hline
\end{tabular}

intraoperative patient temperature. ${ }^{2,8}$ Kallem M D raised the concern the forced air blankets may be associated with SSI for general surgical cohorts. Their review of the literature was inconclusive but given the efficacy of FAWB in preventing IH they recommended practitioners should continue to use them. ${ }^{13}$ However, MacGovern et al., caution that FAWB establish convection currents that mobilise resident air from non-sterile areas into the surgical site leading to deep surgical site infections in orthopaedic patients. ${ }^{14}$ Further evidence is required to establish which warming modality effectively maintains patient normothermia without increasing the risk of SSI. 
Table 4

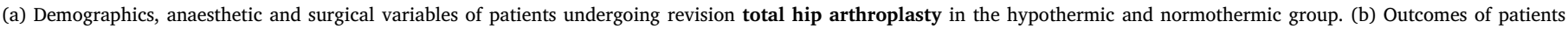
undergoing revision total hiparthroplasty with two cohorts: inadvertent hypothermic and normothermic groups.

\begin{tabular}{|c|c|c|c|c|}
\hline & All & Hypothermic & Normothermic & $P$ value \\
\hline Number of joints & 165 & $10(8.3)$ & $110(92.7)$ & \\
\hline Mean Age \pm SD (range) & $73.6 \pm 11.2(27.0-93.2)$ & $77.8 \pm 7.4(63.5-91.2)$ & $72.4 \pm 11.6(27.0-93.2)$ & 0.15 \\
\hline \multicolumn{5}{|l|}{ Gender (\%) } \\
\hline Male & $66(40.2)$ & $2(20)$ & $48(43.6)$ & 0.15 \\
\hline Female & $98(59.8)$ & $8(80)$ & $62(56.4)$ & \\
\hline \multicolumn{5}{|l|}{ Laterality } \\
\hline Left & $87(52.7)$ & $6(40)$ & $54(49.1)$ & 0.51 \\
\hline Right & $78(47.3)$ & $4(40)$ & $56(50.9)$ & \\
\hline \multicolumn{5}{|l|}{ Indication } \\
\hline Elective & $153(93.3)$ & $10(100)$ & $106(96.4)$ & 0.54 \\
\hline Trauma & $11(6.7)$ & 0 & $4(3.6)$ & \\
\hline Mean ASA grade & $2.42 \pm 0.66$ & $2.40 \pm 0.70$ & $2.38 \pm 0.70$ & 0.89 \\
\hline Mean BMI \pm SD & $29.7 \pm 4.9$ & $29.0 \pm 5.0$ & $29.3 \pm 5.1$ & 0.89 \\
\hline \multicolumn{5}{|l|}{ Anaesthesia type } \\
\hline Regional & $45(27.3)$ & $2(20)$ & $27(24.5)$ & 0.24 \\
\hline General & $116(70.3)$ & $7(70)$ & $81(73.6)$ & \\
\hline LA + Sedation & $4(2.4)$ & $1(10)$ & $2(1.8)$ & \\
\hline Operative time \pm SD & $184.1 \pm 60.6$ & $154.6 \pm 42.1$ & $181.1 \pm 58.5$ & 0.16 \\
\hline Time in theatre $\pm S D$ & $227.3 \pm 67.3$ & $192.1 \pm 49.0$ & $224.7 \pm 66.2$ & 0.13 \\
\hline \multicolumn{5}{|l|}{ Warming Device } \\
\hline \multicolumn{5}{|l|}{ Blanket } \\
\hline Yes & $5(6.4)$ & $2(50)$ & $3(5.6)$ & 0.034 \\
\hline No & $73(93.6)$ & $2(50)$ & $51(94.4)$ & \\
\hline \multicolumn{5}{|l|}{ Fluid Warmer } \\
\hline Yes & $44(56.4)$ & $4(100)$ & $28(51.9)$ & 0.12 \\
\hline No & $34(43.6)$ & 0 & $26(48.1)$ & \\
\hline \multicolumn{5}{|l|}{ Forced Air Blanket } \\
\hline Yes & 77 (98.7) & $4(100)$ & $53(98.1)$ & 1.0 \\
\hline No & $1(1.3)$ & 0 & $1(1.9)$ & \\
\hline \multicolumn{5}{|l|}{ Heated Mattress } \\
\hline Yes & $1(0.6)$ & 0 & $1(0.9)$ & 1.0 \\
\hline \multirow[t]{2}{*}{ No } & $77(98.7)$ & $4(100)$ & $53(98.1)$ & \\
\hline & All $(\mathrm{n}=1096)$ & Hypothermic $(n=10)$ & Normothermic $(\mathrm{n}=110)$ & $P$ value \\
\hline Length of Stay (SD) & $9.72 \pm 13.0$ & $7.9 \pm 5.5$ & $9.2 \pm 11.6$ & 0.75 \\
\hline \multicolumn{5}{|l|}{ 30-day Complication } \\
\hline All & & $3(30)$ & $1(0.9)$ & 0.002 \\
\hline SSSI & $1(0.6)$ & $1(10)$ & 0 & 0.083 \\
\hline DSSI & $2(1.2)$ & $2(20)$ & 0 & 0.006 \\
\hline CVE & 1 & 0 & $1(0.9)$ & 1.0 \\
\hline \multicolumn{5}{|l|}{ 30-day Readmission Rate } \\
\hline All & $11(6.7)$ & 0 & $11(10)$ & 0.60 \\
\hline SSSI & $1(0.6)$ & 0 & $1(0.9)$ & 1.0 \\
\hline DSSI & $2(1.2)$ & 0 & $2(1.8)$ & 1.0 \\
\hline Haematoma & $2(1.2)$ & 0 & $2(4.5)$ & 1.0 \\
\hline Dislocation & $5(3.03)$ & 0 & $5(4.5)$ & 1.0 \\
\hline Anaemia & $1(0.6)$ & 0 & $1(0.9)$ & 1.0 \\
\hline
\end{tabular}


Table 5

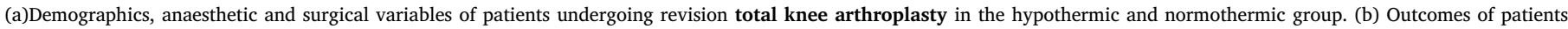
undergoing revision total knee arthroplasty with two cohorts: inadvertent hypothermic and normothermic groups.

\begin{tabular}{|c|c|c|c|c|}
\hline & All & Hypothermic & Normothermic & $P$ value \\
\hline Number of joints & 87 & $3(3.9)$ & $74(96.1)$ & \\
\hline Mean Age \pm SD (range) & $\begin{array}{l}67.6 \pm 12.6 \\
(36.0-90.0)\end{array}$ & $\begin{array}{l}64.7 \pm 1.5 \\
(63.1-66.0)\end{array}$ & $66.5 \pm 12.6(36.0-89.9)$ & 0.81 \\
\hline \multicolumn{5}{|l|}{ Gender (\%) } \\
\hline Male & $53(61.6)$ & $3(100)$ & 43 (58.9) & 0.15 \\
\hline Female & $33(38.4)$ & 0 & $30(41.1)$ & \\
\hline \multicolumn{5}{|l|}{ Laterality } \\
\hline Left & $34(39.5)$ & 0 & $31(42.5)$ & 0.32 \\
\hline Right & $51(59.3)$ & $3(100)$ & $41(56.2)$ & \\
\hline Bilateral & $1(1.2)$ & 0 & $1(1.4)$ & \\
\hline \multicolumn{5}{|l|}{ Indication } \\
\hline Elective & $83(95.4)$ & $3(100)$ & $70(94.6)$ & 0.68 \\
\hline Trauma & $4(4.6)$ & 0 & $4(5.4)$ & \\
\hline Mean ASA grade & $2.29 \pm 0.57$ & $2.33 \pm 0.58$ & $2.22 \pm 0.56$ & 0.70 \\
\hline Mean BMI \pm SD & $32.0 \pm 6.6$ & $36.7 \pm 8.0$ & $31.9 \pm 6.6$ & 0.47 \\
\hline \multicolumn{5}{|l|}{ Anaesthesia type } \\
\hline Regional & $28(32.2)$ & 0 & $24(32.4)$ & 0.79 \\
\hline General & $55(63.2)$ & $3(100)$ & $47(63.5)$ & \\
\hline LA + Sedation & $4(4.5)$ & 0 & $3(4.2)$ & \\
\hline Operative time \pm SD & $181.0 \pm 75.1$ & $157.0 \pm 47.1$ & $175.3 \pm 60.4$ & 0.61 \\
\hline Time in theatre \pm SD & $218.3 \pm 82.0$ & $187.7 \pm 49.0$ & $211.1 \pm 64.9$ & 0.54 \\
\hline Warming device & & & & \\
\hline \multicolumn{5}{|l|}{ Blanket } \\
\hline Yes & $3(9.7)$ & $1(100)$ & $2(8.3)$ & 0.12 \\
\hline No & $28(90.3)$ & 0 & $22(91.7)$ & \\
\hline \multicolumn{5}{|l|}{ Fluid-Warmer } \\
\hline Yes & $16(51.6)$ & $1(100)$ & $12(50)$ & 1.0 \\
\hline No & $15(48.4)$ & 0 & $12(50)$ & \\
\hline \multicolumn{5}{|l|}{ Forced-Air-Blanket } \\
\hline Yes & $30(96.8)$ & $1(100)$ & $24(100)$ & 0 \\
\hline No & $1(3.2)$ & 0 & 0 & \\
\hline \multicolumn{5}{|l|}{ Heated Mattress } \\
\hline Yes & 0 & 0 & 0 & 1.0 \\
\hline No & $31(100)$ & $1(100)$ & $24(100)$ & \\
\hline Variable & All & Hypothermic $(\mathrm{n}=3)$ & Normothermic $(n=74)$ & $P$ value \\
\hline Length of Stay (SD) & $7.5 \pm 7.8$ & $6.33 \pm 2.08$ & $6.9 \pm 7.3$ & 0.90 \\
\hline \multicolumn{5}{|l|}{ 30-day Complication Rate } \\
\hline All & & 0 & $4(5.4)$ & 1.0 \\
\hline $\mathrm{PE}$ & $1(1.1)$ & 0 & $1(1.4)$ & \\
\hline DSSI & $2(2.3)$ & 0 & $2(2.7)$ & \\
\hline CVE & $1(1.1)$ & 0 & $1(1.4)$ & \\
\hline \multicolumn{5}{|l|}{ 30-day Readmission Rate } \\
\hline All & $5(5.7)$ & 0 & $5(6.8)$ & 1.0 \\
\hline $\mathrm{PE}$ & $1(1.1)$ & 0 & $1(1.4)$ & \\
\hline DSSI & $2(2.3)$ & 0 & $2(2.7)$ & \\
\hline Pain & $1(1.1)$ & 0 & $1(1.4)$ & \\
\hline Haematoma & $1(1.1)$ & 0 & $1(1.4)$ & \\
\hline
\end{tabular}




\section{Conclusions}

Our study demonstrates a $3.9 \%$ to $13.2 \%$ rate of IH in TJA, with lower BMI, THA and primary cases as a risk for IH. IH was associated with higher infective complications for rTHA and re-admission for haematoma formation in TKA. We recommend protective steps are taken to maintain patient normothermia in these groups.

\section{Conflict of interest}

No conflicts of interest declared.

\section{References}

1. Buggy DJ, Crossley AW. Thermoregulation, mild perioperative hypothermia and post-anaesthetic shivering. Br J Anaesth. 2000;84:615-628.

2. Mahoney C, Odom J. Maintaining intraoperative normothermia: a meta-analysis of outcomes with costs. AANA J. 1999;67(2):155-164.

3. Yi J, Xiang Z, Deng X, Fan T, Fu R, Geng W. Incidence of inadvertent intraoperative hypothermia and its risk factors in patients undergoing general anesthesia in Beijing: a prospective regional survey. PLoS One. 2015;10(9).
4. Melling AC. Effects of preoperative warming on the incidence of wound infection. Lancet. 2001;358(September (9285)):876-880.

5. Kumar S, Wong PF, Melling AC, Leaper DJ. Effects of perioperative hypothermia and warming in surgical practice. Int Wound J. 2005;2(September (3)):193-204.

6. Frisch NB, Pepper AM, Rooney E, Silverton C. Intraoperative hypothermia in total hip and knee arthroplasty. Orthopedics. 2017;40(January (1)):56-58.

7. Leijtens B, Koëter M, Kremers K, Koëter S. High incidence of postoperative hypothermia in total knee and total hip arthroplasty: a prospective observational study. J Arthroplasty. 2013;28(June (6)):895-898.

8. Fernandes LA, Braz LG, Koga FA. Comparison of peri-operative core temperature in obese and non-obese patients. Anaesthesia. 2012;67(12):1364-1369.

9. Sessler DI. Temperature monitoring and perioperative thermoregulation. Anesthesiology. 2008;109(August (no. 2)):318-338.

10. Jameson SS, Bottle A, Malviya A, Muller SD, Reed MR. The impact of national guidelines for the prophylaxis of venous thromboembolism on the complications of arthroplasty of the lower limb. J Bone Joint Surg Br. 2010;92(January (B1)).

11. Surveillance of surgical site infections in NHS hospitals in England, 2015/16. London: Public Health England; 2016 [December].

12. 12th Annual report. Wales and Northern Ireland: National Joint Registry: National Joint Registry for England; 2015.

13. Kellam MD. Forced-air warming devices and the risk of surgical site infections. AORN J. 2014;100(September (3)):331.

14. McGovern PD, Albrecht M, Belani KG, et al. Forced-air warming and ultra-clean ventilation do not mix. J Bone Joint Surg Br. 2011;93(November (B11)):1537-1544. 